\title{
Albumin Dialysis with Mars in Post-Hepatectomy Liver Failure (PHLF): Experiences from Two HPB Centers
}

Gilg $\mathrm{S}^{1,2}$, Escorsell $A^{3}$, Fernandez $\mathrm{J}^{3}$, Garcia Valdecasas $\mathrm{JC}^{4}$, Saraste $\mathrm{L}^{1,5}$, Wahlin $\mathbf{S}^{1,6}$, Nowak $\mathbf{G}^{1,7}$, Stromberg $\mathrm{C}^{1,2}$, Lundell $\mathrm{L}^{1,2}$ and Isaksson $\mathrm{B}^{1,2}$

${ }^{1}$ Department for Clinical Science, Intervention and Technology (CLINTEC), Karolinska Institutet, Stockholm, Sweden

${ }^{2}$ Department of Surgery at the Centre for Digestive Diseases, Karolinska University Hospital, Stockholm, Sweden

${ }^{3}$ Liver Unit, Hospital Clinic, Barcelona, Spain

${ }^{4}$ Liver Transplantation Unit, Hospital Clinic, Barcelona, Spain

${ }^{5}$ Department of Anaesthesiology and Intensive Care, Spain

${ }^{6}$ Hepatology Division, Centre for Digestive Disease, Spain

${ }^{7}$ Department of Transplantation Surgery, Karolinska University Hospital, Stockholm, Sweden

\begin{abstract}
Aim: To study the impact of molecular adsorbent recirculating system (MARS) treatment on the outcome of patients with post-hepatectomy liver failure (PHLF).

Patients and methods: Records of all patients treated with MARS due to PHLF between January 2003 and December 2013 at the intensive care units of Karolinska University Hospital (KH), Stockholm, Sweden, and Hospital Clinic (HC), Barcelona, Spain, were reviewed retrospectively.

Results: Thirteen patients with PHLF were treated with MARS. Four patients suffered from PHLF secondary to serious post-operative complications and none of them survived. The remaining nine patients fulfilled the 50:50 Balzan criteria for PHLF. In these patients, MARS was commenced on post-operative day (POD) 3-21 (median 8) with a median of three cycles per treatment (range 2-6). In four patients who survived 90 days the treatment was started on POD 7-19 (median 8) with a median of six treatment cycles (range 4-6). In the non-surviving secondary PHLF patients, MARS was started first on POD 17-39 (median POD 32) with a median of 2 completed treatment sessions (range 1-4). No specific complications related to the use of MARS were observed.

Conclusion: The use of MARS in PHLF seems to be feasible and safe and may be a therapeutic option in primary PHLF. Our data suggest that in order to achieve beneficial effects, MARS treatment should be initiated as early as possible in patients with PHLF and a minimum of four consecutive MARS sessions should be administered. Prospective research protocols are needed to further investigate this hypothesis.
\end{abstract}

Keywords: Liver failure; MARS; PHLF

\section{Introduction}

The extent of liver resection and pre-existing liver disease, represent main determinants of the risk of postoperative complications [1-3]. A rare but feared complication is post-hepatectomy liver failure (PHLF), a major source of post-operative morbidity and mortality and an important prognostic factor [4,5]. The pathogenesis of PHLF is still poorly understood and treatment options remain very limited $[6,7]$. In the early 1990 's a promising treatment modality for patients with liver failure was introduced in the form of an extra corporeal, albuminbased liver-dialysis system (Molecular Adsorbent Recirculating System, MARS) [8]. The MARS system has been commercially available since 1999 and its efficacy has been investigated in acute liver failure (ALF) and acute-on-chronic liver failure (ACLF), showing potential benefits in selected populations such as patients with severe hepatic encephalopathy [9], hepato-renal syndrome [10] and advanced liver failure with a MELD score more than 30 [11]. MARS enables removal of both water-soluble and albumin-bound toxins stabilizing hemodynamic parameters with improvement of both liver and kidney function $[12,13]$. However, only few single centre experiences on the use of MARS as a rescue treatment option for PHLF have been reported [13-17]. In addition, these reports contain heterogeneous groups of patients and also applied a variety of different treatment protocols. The outcome is poor with few, if any, surviving patients. Still, this is an ongoing problem and with the application of current treatment paradigms clinicians are not infrequently confronted with a rapidly progressive PHLF patient. The objective of this hypothesis-generating study is to present experience with MARS treatment in the setting of PHLF from two liver centers based on a retrospective analysis of treated patients, presented in the context of a review of the recent published literature.

\section{Patients and Methods}

\section{Patient characteristics}

Sixty-six patients received MARS treatment in the intensive care unit of the Karolinska University Hospital (KH) in Stockholm between November 2003 and December 2013. Indications for MARS were ALF $(\mathrm{n}=24)$, ACLF $(\mathrm{n}=19)$, intractable pruritus in cholestatic liver disease $(\mathrm{n}=4)$ and primary graft dysfunction after liver transplantation $(\mathrm{n}=11)$. In 25 cases MARS was used in ALF as a "bridge" to liver transplantation. Eight patients were treated due to PHLF.

Between January 2008 and December 2013, 33 patients were treated with MARS at the Liver Unit of the Hospital Clínic (HC) in Barcelona. The indications for MARS therapy were: $\operatorname{ALF}(n=14), \operatorname{ACLF}(n=4)$, intractable pruritus $(\mathrm{n}=8)$ and primary graft dysfunction after liver transplantation $(\mathrm{n}=2)$. MARS was used in three patients as a bridge to

${ }^{*}$ Corresponding author: Gilg S, Department for Clinical Science, Intervention and Technology (CLINTEC), Karolinska Institutet and the Department of Surgery at the Centre for Digestive Diseases, Karolinska University Hospital Huddinge, 14186 Stockholm, Sweden, Tel: +46-8-585 80000; E-mail: stefan.gilg@ki.se

Received September 17, 2015; Accepted October 26, 2015; Published November 02 2015

Citation: Gilg S, Escorsell A, Fernandez J, Valdecasas JCG, Saraste L, et al., (2015) Albumin Dialysis with Mars in Post-Hepatectomy Liver Failure (PHLF): Experiences from Two HPB Centers. Surgery Curr Res 6: 252. doi:10.4172/2161-1076.1000252

Copyright: @ 2015 Gilg S et al. This is an open-access article distributed under the terms of the Creative Commons Attribution License, which permits unrestricted use, distribution, and reproduction in any medium, provided the original author and source are credited. 
liver transplantation. During this time period five patients were given MARS due to PHLF.

\section{Selection of PHLF patients for MARS treatment}

The two institutions treated patients with both primary and secondary PHLF. PHLF was considered as "primary" when it developed as a consequence of a small remnant liver volume following major hepatectomy. Secondary PHLF was defined as PHLF occurring as result of liver failure associated with severe post-operative complications such as bleeding, bile leakage, sepsis or multiorgan failure due to, for example cardiac infarction or pulmonary embolism. However, from 2008 and onwards, MARS treatment was only performed in patients with primary PHLF fulfilling the Balzan criteria (the "50:50 rule": bilirubin $>50 \mu \mathrm{mol} / \mathrm{L}$ and prothrombin index $<50 \%$ on POD 5) (18). Before MARS treatment was started, all patients were thoroughly investigated with chest X-ray, urine analyses and ultrasonography, including Doppler assessment of hepatic vessels. Standard medical therapy such as antibiotic treatment, drainage, nutritional support, vaso-active drugs, etc. was given as clinically indicated.

\section{MARS and ICU treatment}

MARS treatment was performed via a double lumen central catheter inserted into the internal jugular vein. A standard continuous renal replacement therapy (CRRT) machine (PRISMA, Gambro, Lund, Sweden) was used for the first four patients in Stockholm and in all patients in Barcelona, whereas a MULTIFILTRATE (Fresenius Medical Care AG, Bad Homburg, Germany) system was used in the latter four Stockholm patients. The CRRT-machine was attached to the MARS monitor (Gambro, Lund, Sweden) in a closed loop albumin circuit. The blood flow on the PRISMA-machine was set to $130-180$ $\mathrm{ml} / \mathrm{min}$ and on the MULTIFILTRATE-machine to $90-150 \mathrm{ml} / \mathrm{min}$. The albumin flow on the MARS-monitor was set to $150 \mathrm{ml} / \mathrm{min}$. The dialysate and replacement fluid flow was set to receive a renal dialysis dose of $35 \mathrm{ml} / \mathrm{kg} / \mathrm{h}$. Standard blood samples were taken at least once daily. Anticoagulation with systemic heparin was used in a minority of cases because of ongoing coagulopathy in most of the treated patients. All Stockholm patients on the MULTIFILTRATE machine received local anticoagulation with citrate. Barcelona patients were scheduled for 2 consecutive sessions in the first 48 hours, followed by one session every other day if the clinical and analytical parameters did not show improvement. In Stockholm a clinical assessment was performed after every MARS treatment to determine the need for continuing treatment. There was a stopping rule for futility. Every session was planned to last a minimum of 6 hours.

\section{Statistics and ethical approval}

Statistical analysis was performed using JMP (Version 5.1.2). The results are reported as mean \pm SD, median (ranges) or $n(\%)$. Students $\mathrm{t}$-test was used where needed and $\mathrm{p}$-values $<0,05$ were considered significant. Local ethics committees approved the study

\section{Results}

The detailed demographic and clinical parameters of the study population are given in Table 1.

The secondary PHLF group consisted of four patients of whom three were treated at $\mathrm{KH}$ and one at $\mathrm{HC}$. The causes of secondary PHLF were:

Patient 1: pulmonary embolism and thrombosis of the superior mesenteric vein on POD 5, followed by dehiscence of a bowel anastomosis on POD 9 and a ruptured pseudo-aneurysm of the hepatic artery on POD 22.

- $\quad$ Patient 2: acute bleeding from the hepatic artery on POD 11 with circulatory instability leading to ischemic liver damage.

- $\quad$ Patient 3: acute bleeding from a giant duodenal ulcer followed by a stroke and episodes of rectal bleedings on POD 17 .

\section{- $\quad$ Patient 4: septic shock of abdominal origin on POD 30.}

In these secondary PHLF patients, MARS treatment was initiated between POD 17 and 39 (median POD 32). Overall the four patients received 1-4 treatment cycles (median 2). None of them survived.

Nine patients with primary PHLF, all fulfilling the 50:50 criteria (18), were enrolled into the study after 2008. Treatment was started between POD 3 and 21 (median POD 8). The treatment was more intensive, with a median of 3 (range 2-6) MARS sessions per patient, compared to the secondary PHLF group. Four patients (two from each participating hospital) of the 9 patients treated for primary PHLF survived 90-days post-operatively and three were three long-term survivors ( $>$ one year).

There was no difference between surviving and non-surviving patients regarding blood samples (both pre and post MARS, Table 2) and onset of MARS treatment (median POD 8; range 7-19). However, in the group of surviving patients treatment was more intensive than in the non-survivor group. Survivors all received four or more sessions (median: 5; range 4-6) compared to non-survivors who received 2-3 sessions (median 2). As seen in Figure 1, the trends in serum bilirubin concentration from surgery to hospital discharge or death were not different between the two surviving patients (1a) and the 3 non-survivors ( $1 \mathrm{~b})$ treated at $\mathrm{KH}$. In all patients, MARS resulted in a decrease in bilirubin with a rebound increase when MARS treatment was terminated. In surviving patients decreasing bilirubin levels were seen during the post-MARS course. Neither creatinin nor INR could distinguish survivors from non-survivors. Both at $\mathrm{KH}$ and $\mathrm{HC}$, no complications could be directly related to the MARS treatment, despite the high-risk profile of the treated patients.

\section{Discussion}

Among liver supportive treatment modalities, MARS is the most widely used, probably because of its safety, its ability to remove both water-soluble and protein-bound toxins, a stabilising effect on circulatory parameters and the potential for improving both liver and kidney function in patients with ALF and AoCLF [11-13,19]. We found MARS in the PHLF situation to be a safe and, contrary to previous reports where an increased risk of severe bleeding was reported, no complications could directly be attributed to the treatment [11]

There is limited data in the available literature regarding MARS treatment in PHLF patients and generally poor results were reported [13-17]. These dismal experiences are somehow in contrast to our results of MARS treatment in PHLF where four of 13 treated patients survived (31\%). It should be emphasized that survival was $44 \%(4 / 9)$ in patients with primary PHLF as defined by the Balzan criteria. In fact, all patients that had completed four or more MARS sessions survived. However, even in our study the outcome was poor when patients were treated due to secondary PHLF, with no survivors. These results partially confirm experiences as earlier reported, even though the subdivision between primary and secondary PHLF was not always clearly defined in these studies $[13,20]$. In addition, these results are also in line with the outcome in reports on patients with other forms of liver failure, 
Citation: Gilg S, Escorsell A, Fernandez J, Valdecasas JCG, Saraste L, et al., (2015) Albumin Dialysis with Mars in Post-Hepatectomy Liver Failure (PHLF): Experiences from Two HPB Centers. Surgery Curr Res 6: 252. doi:10.4172/2161-1076.1000252

Page 3 of 6

\begin{tabular}{|c|c|c|c|c|c|c|c|c|c|c|c|}
\hline Patient & Age & Gender & $\begin{array}{l}\text { Treatment } \\
\text { Year }\end{array}$ & Hospital & $\begin{array}{l}\text { Indication for } \\
\text { Surgery }\end{array}$ & $\begin{array}{l}\text { Surgical } \\
\text { Procedure }\end{array}$ & Liver Failure & $\begin{array}{c}50: 50 \\
\text { Criteria }\end{array}$ & $\begin{array}{l}\text { Treatment } \\
\text { Start (POD) }\end{array}$ & $\begin{array}{l}\text { MARS Cycle } \\
\text { Completed }\end{array}$ & $\begin{array}{l}\text { Outcome } \\
\text { (90 Days) }\end{array}$ \\
\hline 1 & 48 & $\mathrm{~F}$ & 2003 & $\mathrm{KH}$ & $\begin{array}{l}\text { Locally } \\
\text { advanced } \\
\text { gallbladder } \\
\text { cancer } \\
\text { suspicious } \\
\text { gallbladder }\end{array}$ & $\begin{array}{l}\text { Extended } \\
\text { right side } \mathrm{HH} \\
\text { + Whipple } \\
\text { Procedure }\end{array}$ & Secondary & no & 17 & 2 & Died POD 24 \\
\hline 2 & 56 & M & 2005 & $\mathrm{KH}$ & Cancer & $\begin{array}{c}\text { Seg } 5 \text { and } 4 b \\
+ \text { extra bile } \\
\text { ducts }\end{array}$ & Secondary & no & 34 & 1 & Died POD 58 \\
\hline 3 & 53 & M & 2008 & $\mathrm{HC}$ & $\mathrm{CRCm}$ & $\begin{array}{c}\text { Extended right } \\
\text { sided } \mathrm{HH}\end{array}$ & Primary & yes & 3 & 3 & Died POD 7 \\
\hline 4 & 70 & M & 2008 & $\mathrm{KH}$ & $\mathrm{CRCm}$ & $\begin{array}{l}\text { Right sided } \\
\mathrm{HH} \text {, local res } \\
\text { seg } 3\end{array}$ & Secondary & no & 39 & 4 & Died POD 66 \\
\hline 5 & 59 & $M$ & 2008 & $\mathrm{KH}$ & $\mathrm{CCC}$ & Left sided $\mathrm{HH}$ & Primary & yes & 3 & 2 & Died POD 7 \\
\hline 6 & 48 & $M$ & 2008 & $\mathrm{KH}$ & $\mathrm{CRCm}$ & $\begin{array}{c}\text { Right sided } \\
\mathrm{HH} \text {, local res } \\
\text { seg } 3 \text {, caudate } \\
\text { lobe }\end{array}$ & Primary & yes & 8 & 6 & Alive \\
\hline 7 & 77 & M & 2009 & $\mathrm{HC}$ & $\mathrm{CRCm}$ & $\begin{array}{c}\text { Right sided } \\
\text { HH, RFA } \\
\text { lateral Seg }\end{array}$ & Secondary & yes & 30 & 2 & Died POD 34 \\
\hline 8 & 59 & M & 2009 & $\mathrm{KH}$ & $\mathrm{CCC}$ & $\begin{array}{l}\text { Extended right } \\
\text { sided } \mathrm{HH} \text { and } \\
\text { caudate lobe }\end{array}$ & Primary & yes & 7 & 6 & Alive \\
\hline 9 & 61 & $M$ & 2011 & $\mathrm{HC}$ & $\mathrm{CRCm}$ & $\begin{array}{c}\text { Extended right } \\
\text { sided } \mathrm{HH}\end{array}$ & Primary & yes & 8 & 4 & Alive \\
\hline 10 & 59 & $M$ & 2011 & $\mathrm{KH}$ & $\mathrm{CRCm}$ & $\begin{array}{c}\text { Right sided } \\
\mathrm{HH}\end{array}$ & Primary & yes & 8 & 2 & Died POD 18 \\
\hline 11 & 74 & $\mathrm{~F}$ & 2011 & $\mathrm{KH}$ & $\begin{array}{l}\text { Gallbladder } \\
\text { Cancer }\end{array}$ & $\begin{array}{c}\text { Extended right } \\
\text { sided } \mathrm{HH}\end{array}$ & Primary & yes & 6 & 2 & Died POD 17 \\
\hline 12 & 63 & $M$ & 2012 & $\mathrm{HC}$ & MEN-1-met & $\begin{array}{l}\text { Right sided } \\
\mathrm{HH} \text {, local res } \\
\text { seg } 3\end{array}$ & Primary & yes & 21 & 2 & Died POD 45 \\
\hline 13 & 64 & $M$ & 2012 & $\mathrm{HC}$ & $\mathrm{CRCm}$ & $\begin{array}{l}\text { Extended right } \\
\text { sided } \mathrm{HH}\end{array}$ & Primary & yes & 19 & 6 & Alive \\
\hline
\end{tabular}

M (male); F(female); KH, Karolinska Huddinge, Stockholm; HC, Hospital Clinic, Barcelona; CRCm, colorectal cancer metastasis; CCC, cholangiocarcinoma; MEN, multiple endocrine neoplasia, $\mathrm{HH}$, hemihepatectomy; $\mathrm{POD}$, post-operative day.

Table 1: Demographic and clinical data of the study population.

\begin{tabular}{|c|c|c|c|c|c|c|}
\hline \multirow[b]{2}{*}{ Sample } & \multicolumn{2}{|c|}{ pre MARS } & \multirow[b]{2}{*}{$p$ value } & \multicolumn{2}{|c|}{ post MARS } & \multirow[b]{2}{*}{ p value } \\
\hline & suvivors & non survivors & & survivors & non survivors & \\
\hline Bilirubin $(\mu \mathrm{mol} / \mathrm{l})$ & $231( \pm 153)$ & $325( \pm 183)$ & 0,37 & $184( \pm 83)$ & $232( \pm 137)$ & 0,45 \\
\hline INR & $1,7( \pm 0,5)$ & $1,9( \pm 0,4)$ & 0,5 & $2,0( \pm 0,6)$ & $1,7( \pm 0,5)$ & 0,3 \\
\hline ALAT (mikrokat/l) & $1,4( \pm 0,7)$ & $11,1( \pm 18,8)$ & 0,2 & $1,2( \pm 0,5)$ & $3,9( \pm 6,9)$ & 0,3 \\
\hline Creatinine $(\mu \mathrm{mol} / \mathrm{l})$ & $90( \pm 22)$ & $181( \pm 135)$ & 0,08 & $62( \pm 20)$ & $135( \pm 104)$ & 0,07 \\
\hline Platelets $\left(\times 10^{9} / \mathrm{L}\right)$ & $156( \pm 109)$ & $81( \pm 37)$ & 0,3 & $131( \pm 87)$ & $56( \pm 25)$ & 0,2 \\
\hline
\end{tabular}

ALAT: Alanine aminotransferases, values are expressed as mean $\pm \mathrm{SD}$

Table 2: Laboratory values pre and post MARS treatment.

suggesting that a minimum of three MARS cycles is needed to achieve optimal treatment outcomes $[9,21,22]$. However, in the present study MARS treatment was continued only in case of improvement or at least stable disease. Therefore, it is difficult to conclude whether the number of treatments induced an improvement or if the number of treatments just reflects patients with less severe disease burden. Comparing laboratory values at treatment onset and after MARS treatment, we could not find significant differences between survivors and nonsurvivors. However, the number of included patients was little, which compromises the statistical power.

As liver regeneration starts almost immediately after completed hepatectomy [23], it could be argued that an even more successful strategy could be to start liver support therapy earlier in the process of PHLF development. This was supported by recent studies which suggested that a bilirubin $>50 \mu \mathrm{mol} / \mathrm{L}$ already on POD 3 (24) or elevated phosphorus levels as early as on POD 2 might be independent prognostic factors for the development of PHLF [24,25]. However, until proven otherwise, current rational and experience only support 
Citation: Gilg S, Escorsell A, Fernandez J, Valdecasas JCG, Saraste L, et al., (2015) Albumin Dialysis with Mars in Post-Hepatectomy Liver Failure (PHLF): Experiences from Two HPB Centers. Surgery Curr Res 6: 252. doi:10.4172/2161-1076.1000252

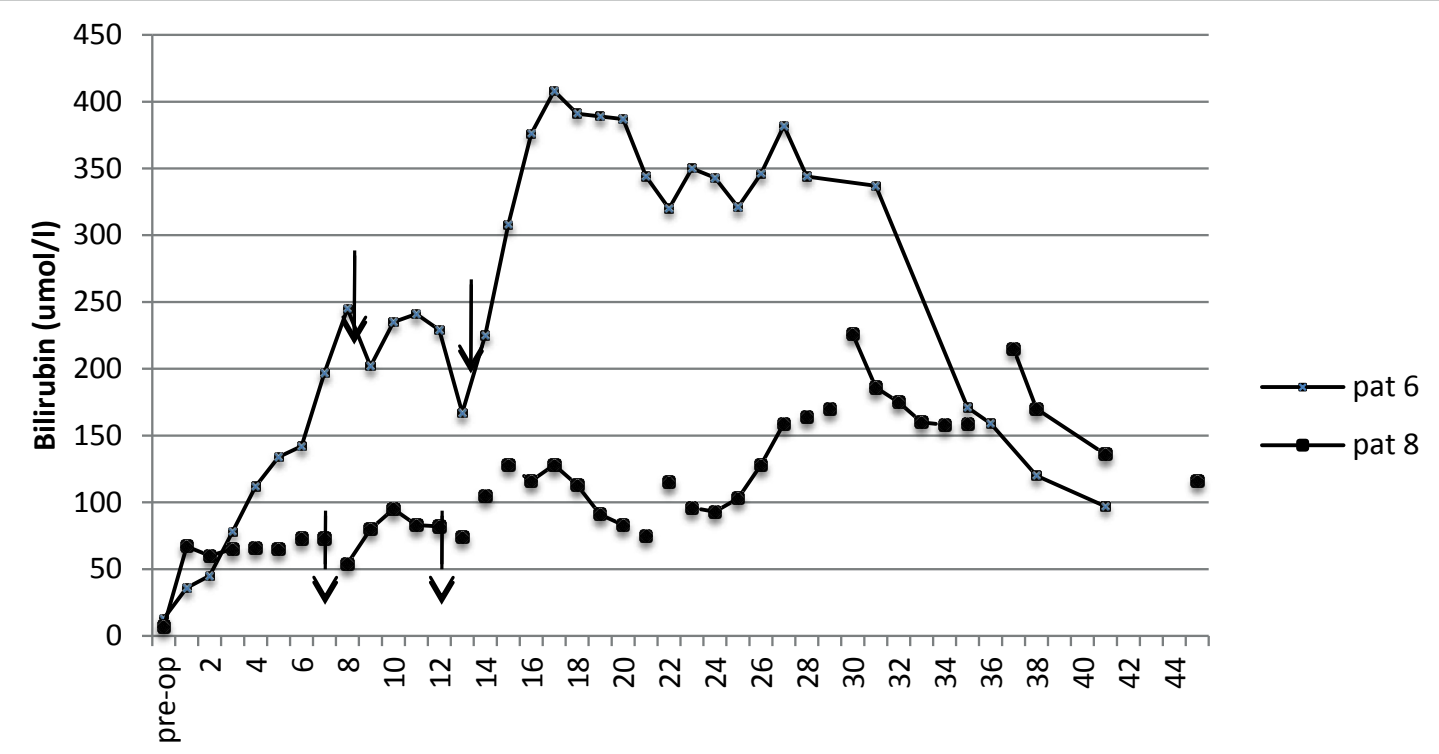

post operative day

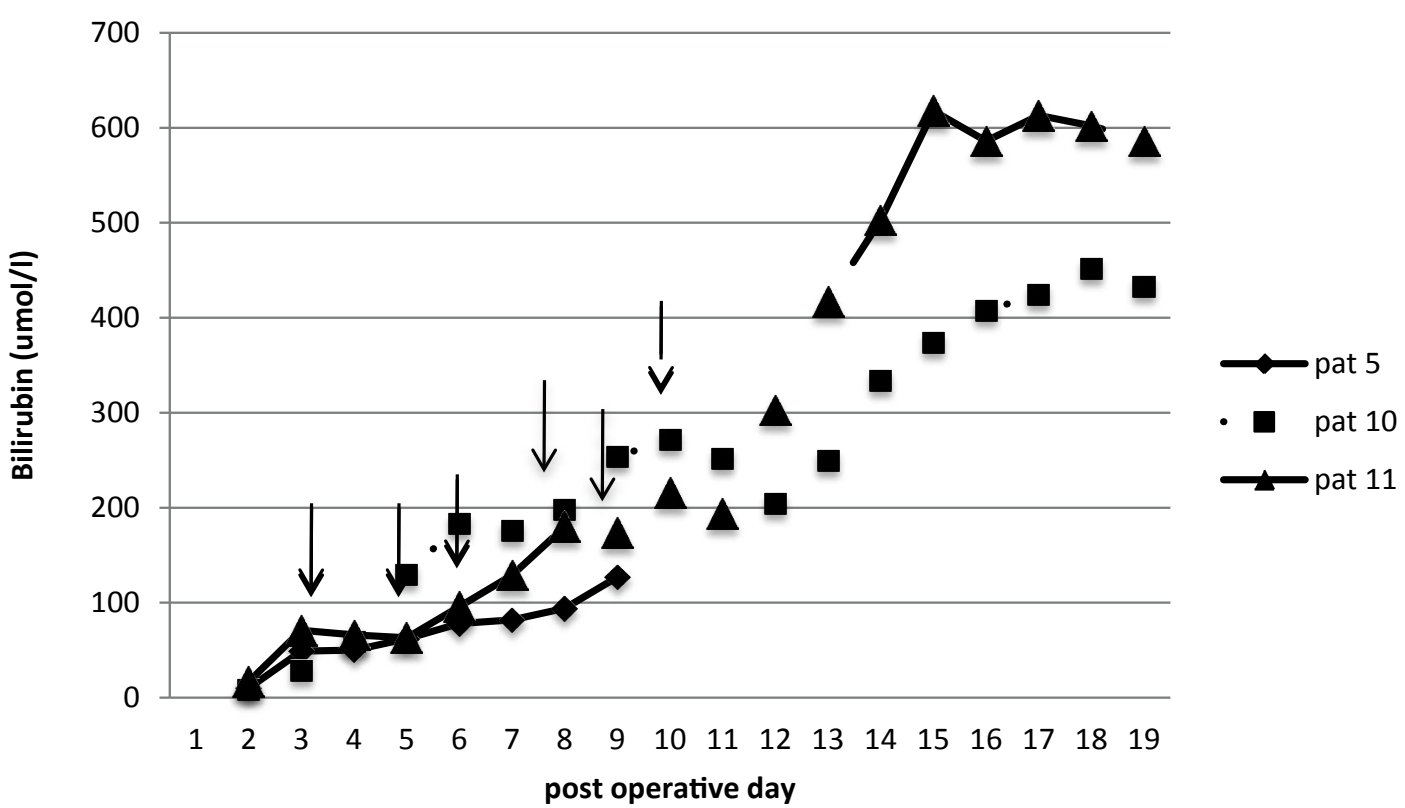

Figure 1: Bilirubin levels before, during and after MARS treatment in patients with PHLF who survived (1a) or did not (1b) at KH. The arrows indicate the first and last treatment session in each patient.

the concept that intervention should be initiated as soon as the 50:50 criteria are fulfilled. Due to the small amount of included patients, the present study did not allow the identification of specific predictors related to mortality in patients suffering of primary PHLF.

After extended liver resections, a too small remnant liver volume or any disturbance in the regeneration process may result in an insufficient capacity of the liver to respond to secondary injuries, and patients frequently succumb to complications (e.g. sepsis, bile leakage) before liver function has entirely been restored [26]. Therefore, it should be beneficial to accelerate the process of liver regeneration. To achieve this MARS treatment in PHLF could provide different, possibly beneficial effects to accelerate liver regeneration.

Firstly, the most important effect of MARS is probably the potential to remove albumin-bound toxins [10]. Albumin serves as a scavenger 
Citation: Gilg S, Escorsell A, Fernandez J, Valdecasas JCG, Saraste L, et al., (2015) Albumin Dialysis with Mars in Post-Hepatectomy Liver Failure (PHLF): Experiences from Two HPB Centers. Surgery Curr Res 6: 252. doi:10.4172/2161-1076.1000252

Page 5 of 6

for reactive oxygen species (ROS) and provides anti- inflammatory and tissue-protecting effects [27]. Detoxification of the circulating plasma albumin may thus improve the anti-oxidative capacity of albumin and thereby reduce the oxidative stress and the on-going damage of the liver tissue, which in turn may facilitate hepatocyte recovery and regeneration. Secondly, up to now no direct effect of MARS treatment on the synthetic capacity of the liver has been demonstrated [13]. Donati et al found an increase of hepatocyte growth factor (HGF) after MARS treatment in patients with AoCLF and ALF and at the same time in certain patients a decrease of IL- 6 and TNF- $\alpha$ [28]. HGF represents a key cytokine, essential for liver regeneration after partial liver resection [23] and accordingly Matsumoto et al found a significant correlation of post-resectional plasma HGF levels and the liver mass on POD 14 [29]. However, none of the studies above was performed in PHLF patients and it is still unclear whether an increase or decrease of this cytokines might be beneficial in the acute PHLF situation. Thirdly, portal hypertension has been identified as an independent risk factor for the development of PHLF after liver resection [30]. Previous studies have demonstrated a significant decrease in portal pressure and stabilization of hemodynamics with an increase in mean arterial pressure (MAP) after MARS treatment in patients with severe alcoholic hepatitis [31] or AoCLF [32]. Despite all these potentially beneficial effects of MARS treatment it has to be mentioned that there is yet no randomized controlled trial that actually could demonstrate a survival benefit when comparing MARS with standard medical therapy, neither in patients with acute [22] nor in patients with acute-on-chronic liver failure [33]. However, this might be different in patients with PHLF and should be investigated thoroughly.

In conclusion, our results are in keeping with the assumptions of Kellersmann et al and Van de Kerkhove et al $[13,14]$, that MARS treatment in patients with PHLF secondary to post-operative complications is currently not justified and that MARS treatment should be initiated as early as possible in primary PHLF. Inclusion criteria for MARS treatment should be based on PHLF definitions with high predictive values for mortality in order to improve patient outcome. The present experience in PHLF shows that MARS seems to be technically feasible and may offer a potential survival benefit. This therapeutic concept and underlying, potentially beneficial effects on liver regeneration have to be further evaluated within the framework of prospective research protocols.

\section{References}

1. Kadry Z, Malekkiani N, Clavien PA (2001) Treatment of primary and secondary liver malignancy. Swiss Med Wkly 131: 338-345.

2. Aloia TA, Fahy BN, Fischer CP, Jones SL, Duchini A, Galati J, et al.(2009) Predicting poor outcome following hepatectomy: analysis of 2313 hepatectomies in the NSQIP database. HPB (Oxford) 11: 510-515.

3. Guglielmi A, Ruzzenente A, Conci S, Valdegamberi A, lacono C (2012) How much remnant is enough in liver resection?. Dig Surg 29: 6-17.

4. Hammond JS, Guha IN, Beckingham IJ, Lobo DN(2011) Prediction, prevention and management of postresection liver failure. British J surg 98: 1188-1200.

5. Helling TS (2006) Liver failure following partial hepatectomy. HPB (Oxford) 8: 165-174.

6. Van den Broek MA, Olde Damink SW, Dejong $\mathrm{CH}$, Lang $\mathrm{H}$, Malago $\mathrm{M}$, Jalan R, et al. (2008) Liver failure after partial hepatic resection: definition, pathophysiology, risk factors and treatment. Liver Int 28: 767-780.

7. Garcea G, Maddern GJ (2009) Liver failure after major hepatic resection. $J$ Hepatobiliary Pancreat Surg 16: 145-155.

8. Stange J, Mitzner S, Ramlow W, Gliesche T, Hickstein H, Schmidt R, et al (1993) A new procedure for the removal of protein bound drugs and toxins.
Asaio J 39: 621-625.

9. Hassanein T, Oliver D, Stange J, Steiner C (2003) Albumin dialysis in cirrhosis with superimposed acute liver injury: possible impact of albumin dialysis on hospitalization costs. Liver int 3: 61-65.

10. Mitzner SR, Stange J, Klammt S, Peszynski P, Schmidt R et al.(2001) Extracorporeal detoxification using the molecular adsorbent recirculating system for critically ill patients with liver failure. J Am Soc Nephrol 17: 75-82.

11. Heemann U, Treichel U, Loock J, Philipp T, Gerken G, et al. (2002) Albumin dialysis in cirrhosis with superimposed acute liver injury: a prospective controlled study. Hepatology 36: 949-958.

12. Nevens F, Laleman W (2012) Artificial liver support devices as treatment option for liver failure. Best Pract Res Clin Gastroenterol 26: 17-26.

13. Van de Kerkhove MP, de Jong KP, Rijken AM, de Pont AC, van Gulik TM (2003) MARS treatment in posthepatectomy liver failure. Liver Int 23: 44-51.

14. Kellersmann R, Gassel HJ, Buhler C, Thiede A, Timmermann W (2002) Application of Molecular Adsorbent Recirculating System in patients with severe liver failure after hepatic resection or transplantation: initial single-centre experiences. Liver 2: 56-58.

15. Rittler P, Ketscher C, Inthorn D, Jauch KW, Hartl WH (2004) Use of the molecular adsorbent recycling system in the treatment of postoperative hepatic failure and septic multiple organ dysfunction--preliminary results. Liver Int 24: 136-141.

16. Inderbitzin D, Muggli B, Ringger A, Beldi G, Gass M, et al. (2005) Molecular absorbent recirculating system for the treatment of acute liver failure in surgical patients. J Gastrointestinal Surg 9: 1155-1161.

17. Chiu A, Chan LMY, Fan ST (2006) Molecular adsorbent recirculating system treatment for patients with liver failure: the Hong Kong experience. Liver Int 26: 695-702.

18. Balzan S, Belghiti J, Farges O, Ogata S, Sauvanet A, et al. (2005) The "50-50 criteria" on postoperative day 5: an accurate predictor of liver failure and death after hepatectomy. Ann Surg 242: 824-828.

19. Bruix J, Sherman (2011) Management of hepatocellular carcinoma: an update. Hepatology 53: 1020-1022.

20. Paugam-Burtz C, Janny S, Delefosse D, Dahmani S, Dondero F, et al. (2009) Prospective validation of the "fifty-fifty" criteria as an early and accurate predictor of death after liver resection in intensive care unit patients. Annals Surg 249: 124-128.

21. Camus C, Lavoue S, Gacouin A, Compagnon P, Boudjema K, et al. (2009) Liver transplantation avoided in patients with fulminant hepatic failure who received albumin dialysis with the molecular adsorbent recirculating system while on the waiting list: impact of the duration of therapy. Ther Apher Dial 13: 549-555.

22. Saliba F, Camus C, Durand F, Mathurin P, Letierce A, et al. (2013) Albumin dialysis with a noncell artificial liver support device in patients with acute liver failure: a randomized, controlled trial. Ann Intern Med 159: 522-531.

23. Michalopoulos GK (2010) Liver regeneration after partial hepatectomy: critical analysis of mechanistic dilemmas. Am J Pathol 176: 2-13.

24. Etra JW, Squires MH, Fisher SB, Rutz DR, Martin BM, et al. (2014) Early identification of patients at increased risk for hepatic insufficiency, complications and mortality after major hepatectomy. HPB (Oxford)16: 875-83.

25. Squires MH, Dann GC, Lad NL, Fisher SB, Martin BM, et al. (2014) Hypophosphataemia after major hepatectomy and the risk of post-operative hepatic insufficiency and mortality: an analysis of 719 patients. HPB (Oxford) 16: 884-891.

26. Mullen JT, Ribero D, Reddy SK, Donadon M, Zorzi D, et al. (2007) Hepatic insufficiency and mortality in 1,059 noncirrhotic patients undergoing major hepatectomy. J Am Coll Surg 204: 854-862.

27. Hetz H, Faybik P, Berlakovich G, Baker A, Bacher A, et al. (2006) Molecular adsorbent recirculating system in patients with early allograft dysfunction after liver transplantation: a pilot study. Liver transplantation 12: 1357-1364.

28. Donati G, La Manna G, Cianciolo G, Grandinetti V, Carretta E, et al. (2014) Extracorporeal detoxification for hepatic failure using molecular adsorbent recirculating system: depurative efficiency and clinical results in a long-term follow-up. Artif Organs 38: 125-134.

29. Matsumoto K, Miyake $Y$, Umeda $Y$, Matsushita H, Matsuda H, et al. (2013) 
Citation: Gilg S, Escorsell A, Fernandez J, Valdecasas JCG, Saraste L, et al., (2015) Albumin Dialysis with Mars in Post-Hepatectomy Liver Failure (PHLF): Experiences from Two HPB Centers. Surgery Curr Res 6: 252. doi:10.4172/2161-1076.1000252

Serial changes of serum growth factor levels and liver regeneration after partia hepatectomy in healthy humans. Int J Mol Sci14: 20877-20889.

30. Allard MA, Adam R, Bucur PO, Termos S, Cunha AS, et al. (2013) Posthepatectomy portal vein pressure predicts liver failure and mortality after major liver resection on noncirrhotic liver. Annals Surg 258: 822-829.

31. Sen S, Mookerjee RP, Cheshire LM, Davies NA, Williams R, et al. (2005) Albumin dialysis reduces portal pressure acutely in patients with severe alcoholic hepatitis. J Hepatology 43: 142-148.

32 Catalina MV Barrio J Anaya F Salcedo M, Rincon D, et al (2003) Hepatic and systemic haemodynamic changes after MARS in patients with acute on chronic liver failure. Liver 23: 39-43.

33. Banares R, Nevens F, Larsen FS, Jalan R, Albillos A, et al. (2013) Extracorporea albumin dialysis with the molecular adsorbent recirculating system in acute-onchronic liver failure: the RELIEF trial. Hepatology 57: 1153-1162. 